\title{
Criterion distances and correlates of active transportation to school in Belgian older adolescents
}

Delfien Van Dyck ${ }^{1,2^{*}}$, Ilse De Bourdeaudhuij ${ }^{2}$, Greet Cardon², Benedicte Deforche $e^{1,2,3}$

\begin{abstract}
Background: Since physical activity levels in older adolescents have the potential to be increased by stimulating active transportation to school (ATS), the most important correlates of ATS should be determined before developing interventions, especially in those adolescents for whom the distance to school is feasible for active commuting. The main aims of this study were to determine criterion distances for ATS in Belgian older adolescents, to examine multidimensional correlates of ATS in adolescents living within a feasible distance from school and to investigate the associations of ATS with total physical activity and with other physical activities besides ATS.

Methods: In total, 1281 older adolescents (17-18 years) from 20 general secondary schools in East- and WestFlanders completed a questionnaire on physical activity behaviors, demographic factors and psychosocial and physical environmental correlates of physical activity. Distance to school was objectively measured using Routenet online route planner.

Results: In total, 58.4\% of the participants commuted actively to school. The criterion distance for ATS could be set at eight kilometers for cycling and two kilometers for walking. For those adolescents living within a feasible distance for ATS, gender, smoking status, walkability of the neighborhood and social modeling were associated with transportation mode choice. ATS was positively associated with total physical activity, but not significantly related to min/week of other physical activities.

Conclusions: For older adolescents living within eight kilometers of their school, interventions taking into account the correlates found to be related to ATS could possibly be effective to enhance ATS and to increase total physical activity levels. In the context of the overall physical activity decline in adolescence, also interventions targeting physical activity behaviors of adolescents living further away from school might be needed, but these interventions should probably emphasize alternative strategies.
\end{abstract}

\section{Background}

In most developed nations, physical activity (PA) declines in adolescence with considerable proportions of adolescents not meeting the PA guideline of 60 minutes of moderate to vigorous PA daily [1]. To increase daily PA in adolescents, active transportation to school (i.e. walking and cycling to school; ATS) could be an important contributor [2]. Several studies in adolescents have shown that ATS is associated with higher overall moderate-to-vigorous PA [3,4], higher fitness levels [5,6] and higher daily energy expenditures [2] compared to passive commuting.

\footnotetext{
* Correspondence: delfien.vandyck@ugent.be

${ }^{1}$ Fund for Scientific Research Flanders (FWO), Brussels, Belgium

Full list of author information is available at the end of the article
}

Nevertheless, before developing interventions enhancing ATS in adolescents, the most important multidimensional determinants of the target behavior need to be identified. Ecological models state that PA (including ATS) is influenced by an interplay between sociodemographic, psychosocial and physical environmental factors and that each of these factors needs attention in research $[7,8]$.

Most research investigating correlates of ATS in adolescents only focused on young adolescents (12-16 years). For this age group, sociodemographic correlates of ATS are consistent with boys and low socioeconomic status (SES) adolescents having higher ATS rates than girls and high-SES adolescents [8-13]. Some studies in young adolescents also investigated

\section{Biomed Central}


psychosocial correlates like social modeling, perceived barriers and attitude towards PA, but no significant associations with ATS have been found until now $[9,10]$. For neighborhood physical environmental factors, some evidence showed that living in urban areas [9], perceiving more land use mix [12] and perceiving higher connectivity [13] are related to more ATS in young adolescents, but the most consistent physical environmental correlate in this age group is distance to school. Many studies found distance to school to be negatively associated with ATS $[9,12,14,15]$.

Research on ATS correlates in older adolescents (16-18 years) is much sparser. Only two studies in this age group were identified [16,17]. Nelson and colleagues [16] found that boys, adolescents living in densely populated areas and those living closer to school were more likely to do ATS, while Robertson-Wilson and colleagues [17] showed that boys, non-smoking adolescents and those attending an urban school were more likely to commute actively. Because limited evidence on the most important correlates of ATS in older adolescents exists, further research in this age group is necessary. Moreover, Belgian adolescents are allowed to drive a moped from the age of 16 , possibly causing a decrease in ATS in older adolescents. Furthermore, since PA tends to track stronger from late adolescence to adulthood than from childhood or early adolescence to adulthood [18], enhancing ATS in older adolescence affect ATS in adult life positively. The transition from high school to university or college (at the age of 18 in Belgium) has also been shown to be a critical period for decreasing PA levels and weight gain $[19,20]$. Since 16-18 year old adolescents are supposed to undergo this transition in the near future, interventions increasing ATS in older adolescents might help to sustain the amount of active transportation after the transition.

As mentioned above, previous studies showed that distance to school was the most consistent physical environmental barrier to ATS in young adolescents $[9,12,14-16]$. Nonetheless, this distance barrier is very difficult to tackle since it is not possible to force adolescents to move closer to school or to choose a school closer to their home. However, a UK study in 15-17 year old adolescents showed that $40 \%$ of the adolescents commuting to school by car, lived within $4.0 \mathrm{~km}$ of their school, which might be a feasible distance for ATS. Consequently, investigating the multidimensional correlates of transport mode choice in adolescents for whom the distance to school is feasible for ATS, is important.

In that context, an important issue is the determination of a criterion distance within which ATS is feasible. According to a UK study in 15-17 year old adolescents, over $80 \%$ of the adolescents walking and cycling to school lived within respectively $2.4 \mathrm{~km}$ and $4.0 \mathrm{~km}$ from school [16]. Consequently, these distances were defined as criterion distances. Once distances to school exceeded these criteria, the percentage of adolescents commuting actively to school dropped clearly. To our knowledge, no other European studies have determined such criterion distances for ATS in adolescents. Since cycling rates are higher in Belgium than in England [21] and criterion distances can differ across age groups, it is recommended to determine country- and age-specific criterion distances.

Consequently, our main study aims were 1) to determine criterion distances for walking and cycling to school in Belgian older adolescents (17-18 years), 2) to examine sociodemographic, psychosocial and physical environmental correlates of ATS in those Belgian adolescents for whom the distance from home to school is feasible for active transportation, and 3) to investigate whether ATS is positively associated with total PA and with other PA besides ATS.

\section{Methods}

\section{Participants and protocol}

In total, 1281 adolescents $(57.3 \%$ female, $17.1 \pm 0.5$ years) from 20 general secondary schools in East- and West-Flanders participated in the study. All adolescents attended the last year of secondary school. To recruit participants, 58 randomly selected schools were contacted by phone, of which 20 agreed to participate (response rate schools $=34.5 \%)$. Informed consent was obtained from school directors, parents and students. The study protocol was approved by the ethical committee of Ghent University Hospital. All participants completed a questionnaire on PA behaviors and correlates during classes, under supervision of a research assistant. Weight and height were objectively measured according to international standards [22].

\section{Measures}

\section{Demographic variables}

Self-reported demographic variables included gender, age, living situation, living environment, smoking status, parental educational level, parental working status, home address and school address.

\section{Psychosocial variables}

All questions were derived from previous studies in adults and adolescents [23-25]. Social modeling, social norm, social support, self-efficacy and attitude towards PA were included. Social modeling was measured by asking how frequently family and friends participated in PA (two items, Cronbach's alpha $(\alpha)=0.62$ ). Social norm was assessed by asking if participants believed that family and friends wanted them to exercise (two items, $\alpha=0.77$ ). To investigate social support, participants were asked how often family and friends exercised 
together with them, invited them to exercise and encouraged them to participate in PA (six items, $\alpha=$ 0.74). The level of self-efficacy was obtained by asking how confident they were to be physically active under 14 potentially difficult situations (e.g. when tired, family expectations; $\alpha=0.91$ ). Attitude towards PA was calculated by subtracting the total perceived barriers towards PA (e.g. lack of time, lack of energy; 26 items, $\alpha=0.94$ ) from the total perceived benefits towards PA (e.g. enjoyment, weight loss; 18 items, $\alpha=0.91$ ). This calculation method follows the principles of the Health Belief Model [26], which explains that general attitude can be expressed as perceived benefits minus perceived barriers. All psychosocial correlates were rated on a 5-point Likert scale.

\section{Perceived neighborhood physical environmental factors}

To assess the perceived neighborhood environment, the Flemish NEWS questionnaire was used [27]. 'Neighborhood' was defined as 'the direct environment, everywhere within a 10-15 minute walk of your home'. Only those neighborhood physical environmental factors that have been shown to be consistently associated with active transportation in previous studies [28], were included in the analyses. Moreover, physical environmental factors being irrelevant for ATS, like access to recreational facilities and amount of home PA equipment, were not included in the analyses. Factors included were residential density, land use mix diversity and access, street network connectivity, availability and quality of walking and cycling infrastructures, safety for bicycle theft and perceived traffic safety.

The Flemish NEWS has acceptable to good reliability (intraclass correlation coefficients between 40 and .97) and acceptable validity (coefficients between .21 and .91) [27]. All environmental factors were rated on a 4-point scale, except for residential density (three-point) and land use mix diversity (5-point). Because of high intercorrelations $(\geq 0.40)$ between residential density, land use mix diversity, land use mix access and connectivity, a 'walkability Z-score' was calculated based on the Zscores of these four scales. This walkability score was based on the walkability formula of Frank and colleagues [29]: walkability $=\mathrm{z}$-score residential density $+2^{*} \mathrm{z}-$ score connectivity $+\mathrm{z}$-score land use mix. The walkability z-score was used in all analyses.

\section{Physical activity and transportation mode to school}

Physical activity was determined using a paper-and-pencil version of the Flemish Physical Activity Questionnaire, which has been validated in a computerized version [30]. In that questionnaire, transportation mode to school (walking, cycling, passive transportation) was queried. Passive transportation included transportation by car, moped and public transport. For some analyses, a dichotomized variable (active versus passive transportation) was constructed. Moreover, min/week of ATS, min/week of active transportation in leisure-time and $\mathrm{min} /$ week of leisure-time sports were assessed. Time spent in PA besides ATS (= other PA) was calculated by subtracting min/week of ATS from the total amount of PA (min/ week). Total PA was obtained by summing up min/week of ATS, min/week of active transportation in leisure-time, $\mathrm{min} /$ week of leisure-time sports and min/week of sports at school.

\section{Distance to school}

Distance from the participants' home to school was objectively measured using Routenet online route planner http://www.routenet.be, taking into account both school and home address data. The shortest route from home to school was used.

\section{Data analysis}

Descriptive statistics and criterion distances for walking and cycling to school were analyzed using SPSS 16.0. To determine criterion distances for ATS, cumulative percentages of participants commuting actively to school per covered distance (ranges of $1 \mathrm{~km}$ ) were examined. Criterion distances were set at a distance within which approximately $85 \%$ of the active commuters lived.

Multilevel regression analyses were conducted using MLwiN version 2.10. Multilevel modeling (two-level: participant-school) was applied to take into account clustering of paticipants within schools. To examine associations between the independent variables (sociodemographics, physical environmental perceptions, psychosocial factors) and transportation mode choice (active/passive transportation: dummy variable), twolevel logistic regressions were used. Odds ratios with confidence interval (95\%) are given for each independent variable. To investigate associations of transportation mode choice (independent variable: dummy) and $\mathrm{min} /$ week of ATS (independent variable) with total PA (dependent variable) and with the amount of other PA (dependent variable), two-level linear regression models were constructed. These analyses were controlled for the significant correlates of transportation mode choice. For all analyses, significance was set at $\mathrm{p} \leq 0.05$.

\section{Results}

\section{Sample characteristics}

Sociodemographic characteristics, as well as mean scores of the psychosocial and physical environmental variables are shown in Table 1 . Of the total sample, $6.6 \%$ walked to school, $51.8 \%$ cycled to school and $41.5 \%$ used passive transportation. Mean overall distance from home to school was $6.57(6.17) \mathrm{km}$. For the adolescents walking or cycling to school, mean distance was $1.31(1.03) \mathrm{km}$ and $4.80(2.87) \mathrm{km}$ respectively. For the passive commuters, mean distance $9.74(8.04) \mathrm{km}$. 
Table 1 Descriptive characteristics of the sample

Variable Total sample $(\mathrm{n}=$

1281)

Sociodemographic characteristics

Gender (\%)

Male

Female

Age (mean (SD))

Living situation (\%)

Living with both parents

Not living with both parents

Living environment (\%)

Coastal environment

Countryside

Village

(Sub)urban environment

Educational level mother (\%)

No college/university degree

College/university degree

Educational level father (\%)

No college/university degree

College/university degree

Working status mother (\%)

Not working

Working

Working status father (\%)

Not working

Working

Smoking status (\%)

Non-smoker

Smoker

Body Mass Index in $\mathrm{kg} / \mathrm{m}^{2}$ (mean (SD))

Boys

Girls

Psychosocial factors

Social modeling

Social norm

Social support

Self-efficacy

Attitude towards PA

Neighborhood physical environmental perceptions

Walkability Z-score

Walking infrastructure

Cycling infrastructure

Safety for cycling

Traffic safety

Mode of transportation to school (\%)

Walking

Cycling

Passive (car, public transit, motor)

Distance to school in km (mean (SD))

Overall

Walking
$21.84(2.96)$

$21.60(2.84)$

42.7

57.3

$17.14(0.51)$

\section{5}

19.5

0.4

18.6

42.5

38.6

32.8

67.2

35

65

13

87

3

97

88.9

11.1

$3.35(0.78)$

$3.18(1.10)$

$2.51(0.74)$

$3.44(0.86)$

$1.32(1.13)$

0.01 (2.89)

$2.74(0.61)$

$2.34(0.56)$

$2.43(0.40)$

$2.74(0.49)$
Table 1 Descriptive characteristics of the sample (Continued)

\begin{tabular}{ll}
\hline Cycling & $4.80(2.87)$ \\
Passive transportation (car, public transit, & 9.74 (8.04) \\
motor) & \\
\hline
\end{tabular}

$\mathrm{SD}=$ standard deviation

Criterion distance for different transportation modes

Table 2 shows the (cumulative) percentages of participants walking, cycling and commuting passively to school per covered distance. In total, $83.5 \%$ of the adolescents walking to school lived within 2.0 kilometers from school. The other $16.5 \%$ lived within 5.0 kilometers. Of the adolescents who cycled to school, $85.6 \%$ lived within 8.0 kilometers from school and $94 \%$ within 10 kilometers. Approximately $44 \%$ of the passive commuters also lived within 8.0 kilometers from school.

The results shown in Figure 1 confirm these findings. In that figure, the percentages of cyclists, walkers and passive commuters living at each distance from school are presented. For walking, a clear breaking point in the curve can be observed at $2.0 \mathrm{~km}$. For cycling, the breaking point is less clear, but at a distance of $8.1-9.0 \mathrm{~km}$ from home to school, the cycling curve crosses the passive commuting curve. At that distance, the percentage of passive commuters becomes higher (53.6\%) than the percentage of cyclists (46.4\%).

\section{Correlates of transportation mode choice}

Based on the results from Table 2 and Figure 1 criterion distances could be set at two kilometers for walking and eight kilometers for cycling. Consequently, to examine correlates of transportation mode choice in adolescents for whom distance to school is feasible for ATS, only participants living within 8 kilometers from school were included in the regression analyses (i.e. 888 adolescents).

The logistic regression analyses (Table 3) revealed that gender, smoking status, walkability of the neighborhood and social modeling were significantly associated with transportation mode choice. Girls $(\mathrm{OR}=0.58 ; 95 \% \mathrm{CI}=$ $0.41-0.84)$ and smokers $(\mathrm{OR}=0.61 ; 95 \% \mathrm{CI}=0.41-0.92)$ were less likely to do ATS than boys and non-smokers. Moreover, adolescents perceiving higher neighborhood walkability $(\mathrm{OR}=1.10 ; 95 \% \mathrm{CI}=1.02-1.17)$ and more social modeling $(\mathrm{OR}=1.23 ; 95 \% \mathrm{CI}=1.01-1.51)$ were more likely to do ATS than those perceiving lower walkability and less social modeling. For the other sociodemographic, physical environmental and psychosocial factors, no significant results were found.

Associations of transport mode choice, min/week of active transportation to school with total PA and other PA

For these analyses, two linear regression models were constructed. In the first model, the associations of transport 
Table 2 Distance covered by transportation mode

\begin{tabular}{|c|c|c|c|c|c|c|}
\hline \multirow[t]{2}{*}{ Distance (km) } & \multicolumn{2}{|c|}{ Walking $(n=85)$} & \multicolumn{2}{|c|}{ Cycling ( $n=664)$} & \multicolumn{2}{|c|}{ Passive transport $(n=532)$} \\
\hline & $\%$ & Cum\% & $\%$ & Cum\% & $\%$ & Cum\% \\
\hline $0.1-1.0$ & 50.6 & 50.6 & 3.8 & 3.8 & 0.2 & 0.2 \\
\hline $1.1-2.0$ & 32.9 & 83.5 & 13.2 & 17.0 & 1.2 & 1.4 \\
\hline $2.1-3.0$ & 8.9 & 92.4 & 1.81 & 35.0 & 4.7 & 6.1 \\
\hline $3.1-4.0$ & 2.5 & 94.9 & 12.2 & 47.2 & 4.7 & 10.8 \\
\hline $4.1-5.0$ & 5.1 & 100.0 & 12.5 & 59.7 & 7.4 & 18.2 \\
\hline $5.1-6.0$ & & & 9.5 & 69.3 & 8.8 & 27.0 \\
\hline $6.1-7.0$ & & & 8.1 & 77.7 & 8.0 & 35.0 \\
\hline $7.1-8.0$ & & & 8.2 & 85.6 & 9.2 & 44.2 \\
\hline $8.1-9.0$ & & & 6.2 & 91.8 & 9.2 & 53.4 \\
\hline $9.1-10.0$ & & & 2.2 & 94.0 & 8.4 & 61.8 \\
\hline$>10.0$ & & & 6.0 & 100.0 & 38.2 & 100.0 \\
\hline
\end{tabular}

$\mathrm{km}=$ kilometer

Cum $\%$ = cumulative percent

mode choice (active versus passive) with total PA and with other PA were examined. This model showed that, after controlling for the significant correlates of transport mode choice (i.e. gender, smoking status, walkability score and social modeling), active commuting to school was positively associated with total PA $(\beta=0.206, \mathrm{SE}=0.014, \mathrm{p}<$ 0.001 ), but not significantly associated with $\mathrm{min} /$ week of other PA ( $\beta=0.033, \mathrm{SE}=0.037, \mathrm{p}=$ n.s.).

In the second model, the associations of the amount of ATS (in min/week) with total PA and with other PA were investigated. Results showed that, after controlling for the same correlates, min/week of ATS was positively related to total PA $(\beta=0.106, \mathrm{SE}=0.006, \mathrm{p}<0.001)$, but not significantly associated with $\mathrm{min} /$ week of other PA $(\beta=0.008, \mathrm{SE}=0.017, \mathrm{p}=$ n.s. $)$.

\section{Discussion}

Our results showed that $58.4 \%$ of the adolescents commuted actively to school. Of these active commuters, $88.7 \%$ cycled to school and $11.3 \%$ walked to school.

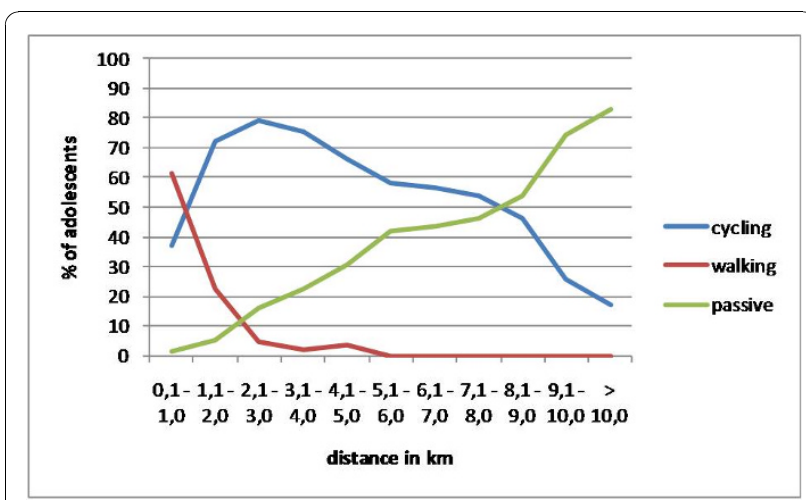

Figure 1 Percentage of adolescents per transportation mode for each covered distance.
These percentages are higher than those found in the UK and Canada, where respectively $37.5 \%$ and $42.5 \%$ of the 15-18 year olds engaged in ATS [16,17]. Nevertheless, a Portuguese study in 13-18 year old adolescents found that $66.3 \%$ of the participants commuted actively to school, which is higher than the percentages found in this study [31]. In contrast with our findings, these other studies reported a much higher prevalence of walking to school $(85.8 \%$ to $92.1 \%$ of the active commuters) than cycling to school (7.9 to $14.2 \%)$. The high prevalence of cycling to school found in our 17-18 year old participants could possibly be contributed to the flat landscape, long cycling tradition and cycling-friendly infrastructures in Belgium, resulting in high cycling rates in all age groups [[21,32], Cardon et al, unpublished observations]. Moreover, in Belgium a driver's license (for cars and motorbikes) can only be obtained from the age of 18 years, so adolescents in the last year of secondary school are not yet allowed to drive to school.

The results of the first research question showed that the criterion distance for ATS in older Belgian adolescents could be set at eight kilometers for cycling (85\% of the cyclists lived within this distance from school) and two kilometers for walking $(83.5 \%$ of the walkers lived within this distance). Nevertheless, the number of adolescents walking to school was limited, so further research is necessary to confirm this two kilometer criterion distance. To our knowledge, only one other study determined criterion distances in this age group [16]. In that study, criterion distances were $2.4 \mathrm{~km}$ for walking and $4.0 \mathrm{~km}$ for cycling. The criterion for walking is comparable between the two studies, but for cycling a greater distance was found in our study. This difference could also be due to the high cycling rates, cyclingoriented culture, flat landscape and cycling-friendly infrastructures in Belgium. 
Table 3 Logistic multi-level analyses of sociodemographic, physical environmental and psychosocial correlates of transportation mode to school

\begin{tabular}{|c|c|c|c|}
\hline \multicolumn{4}{|c|}{ Dependent variable: Transportation mode to school: $0=$ passive transportation, $1=$ active transportation } \\
\hline Predictor & $\beta$ (SE) & Odds ratio & $95 \% \mathrm{Cl}$ \\
\hline Gender (ref: male) & $-0.539(0.184)$ & 0.58 & $0.41,0.84^{*}$ \\
\hline Educational attainment mother (ref: no college/univ) & $-0.176(0.190)$ & 0.84 & $0.58,1.21$ \\
\hline Educational attainment father (ref: no college/univ) & $0.146(0.187)$ & 1.16 & $0.80,1.67$ \\
\hline Smoking status (ref: non-smoker) & $-0.488(0.207)$ & 0.61 & $0.41,0.92 *$ \\
\hline Body Mass Index & $0.028(0.028)$ & 1.03 & $0.97,1.09$ \\
\hline Walkability Z-score & $0.091(0.033)$ & 1.10 & $1.02,1.17^{*}$ \\
\hline Walking infrastructure & $0.127(0.173)$ & 1.14 & $0.81,1.60$ \\
\hline Cycling infrastructure & $-0.024(0.176)$ & 0.98 & $0.69,1.38$ \\
\hline Safety for bicycle theft & $0.232(0.212)$ & 1.26 & $0.83,1.91$ \\
\hline Traffic safety & $0.117(0.175)$ & 1.12 & $0.80,1.58$ \\
\hline Social modeling & $0.211(0.102)$ & 1.23 & $1.01,1.51 *$ \\
\hline Social norm & $-0.016(0.088)$ & 0.98 & $0.83,1.17$ \\
\hline Social support & $0.089(0.134)$ & 1.09 & $0.84,1.42$ \\
\hline Self-efficacy & $0.033(0.130)$ & 1.03 & $0.80,1.33$ \\
\hline Attitude towards PA & $0.111(0.098)$ & 1.12 & $0.92,1.35$ \\
\hline
\end{tabular}

$\mathrm{SE}=$ standard error, $95 \% \mathrm{Cl}=95 \%$ confidence interval, $\mathrm{PA}=$ physical activity

${ }^{*} \mathrm{p}<0.05$

Nonetheless, more than $40 \%$ of the adolescents living within eight kilometers from school commuted passively to school. These adolescents are important targets for behavior change, since distance to school should be no major barrier. When focusing on those adolescents living within eight kilometers, gender, smoking status, social modeling and perceived neighborhood walkability were associated with transport mode choice. Other studies in young adolescents also found that boys and nonsmoking adolescents were more likely to commute actively than girls and smokers $[4,9,10,17]$. Consequently, future interventions could focus specifically on these at-risk groups. Especially for smoking adolescents, a multibehavioral intervention targeting both PA and smoking behavior could be relevant. In contrast with other studies in young adolescents [11,13], parental education did not contribute to the likelihood of ATS. This might be due to a lack of variety in educational levels in our sample. Because only adolescents attending general secondary schools were included, educational levels were rather high. Nevertheless, when comparing the high and low SES adolescents (32.5\% of the participants' mothers had a low educational level [33]), no differences were found for transport mode choice $\left(\chi^{2}=0.54, \mathrm{p}=\mathrm{n}\right.$. s.). This is promising, suggesting that interventions targeting ATS might be effective for both high and low SES older adolescents.

Concerning the psychosocial correlates, only PA levels of family and friends were positively associated with ATS. If future studies can confirm this result, it would give added value to involve the social environment (family and friends) of adolescents in interventions to increase ATS. The few other studies that included psychosocial factors did not find any significant associations with ATS in young adolescents $[9,10]$. A possible explanation for this limited evidence could be that active transportation is rather a habitual behavior than as a conscious choice, based on psychosocial constructs [34]. So, a supportive physical environment might possibly be more important to stimulate ATS than psychosocial factors.

Adolescents perceiving high neighborhood walkability were more likely to do ATS. Other studies including street connectivity $[10,13]$, population density [16] or land use mix [35] as a potential correlate of adolescents' transport mode choice, found similar results. However, one Belgian study comparing PA of 12-18 year old adolescents living in a high-walkable town centre with PA of adolescents living in a less-walkable suburb, found similar percentages of active commuters in both neighborhoods [36]. This inconsistency across Belgian studies could possibly be explained by the age difference across the samples and the different methods used to measure walkability (perceptions versus objective measures). Because in general, study results on the importance of walkability features to encourage ATS in children and adolescents are still inconclusive [36-38], further research is recommended. Furthermore, walkability characteristics of school environments and the route to school should be included in future studies, since not only the neighborhood around their home, but also the school environment is important in explaining 
adolescents' PA [39]. Perceptions of availability and quality of walking and cycling infrastructures, safety for bicycle theft and traffic safety did not contribute significantly to the likelihood of ATS in this study. Especially traffic safety might be of higher importance in children and younger adolescents, since other studies showed that parental perceptions of safety are crucial in the decision about a child's travel mode [40,41].

The results of the last research question showed that active (versus passive) transportation to school and $\mathrm{min} /$ week of ATS were positively associated with total PA, but not with other PA besides ATS. These findings suggest that the higher amounts of total PA in active commuters were caused by ATS only. Many other studies have also found a positive association between ATS and total PA $[2-4,42]$ but mixed results have been found for the association between ATS and other PA. A Portuguese study showed that ATS was positively related to non-organized other PA among 13-16 year old boys, but not among girls [31] and Landsberg and colleagues [4] found similar gender-specific results in 14-year-old German adolescents. A study in Filipino youth supported our results and found that the higher amount of total energy expenditure in active commuters was due to active commuting only [2]. When interpreting our results and the findings of Tudor-Locke and colleagues [2], it is positive that adolescents doing ATS appear not to compensate this healthy behavior with less PA in other domains. Moreover, the finding that ATS was not associated with other PA suggests that not only those adolescents who already engage in many leisure-time PA commute actively. This is promising for future interventions, because as long as the distance is feasible, ATS could be stimulated in both active and less active older adolescents. However, more research is needed to confirm our findings. Future research should also address possible associations between ATS, total PA and health parameters, since no consensus on the health effects of ATS is reached yet $[4,31,43]$.

Strengths of this study firstly include the large study sample. Secondly, the study was executed in 17-18 year old adolescents. Almost no other studies have investigated the ATS correlates in this age group, and since the transition from high school to university has been shown to be a critical period to decrease PA $[19,20]$, research in this age group is important. Thirdly, validated questionnaires were used. Moreover, distance to school was measured objectively. Some study limitations also need to be acknowledged. First, only self-reported PA was assessed. Future studies should consider including objective PA measures, since self-report measures possibly suffer from social desirability and over-reporting [24]. Second, the questions on psychosocial correlates did not specify a type or domain of PA, so it might be that the participants tended to consider mainly leisure-time PA when responding. This lack of specificity might have influenced the present results. Third, only adolescents attending general secondary schools were included, limiting the generalizability of the results. Fourth, only the main transport mode of the adolescents was captured in the questionnaire. Probably, some adolescents used mixed transportation (e.g. combination bicycle - public transit), which is healthier than using only passive transportation. Fifth, in the questionnaire, passive transportation was not specified in terms of car use, public transit or moped use. For other research questions, this information would be interesting. Sixth, no characteristics of the school environment (physical environment, school policies, encouragement of ATS,...) and of the route to school were included in this study, while these factors are probably associated with the amount of ATS. Seventh, the online routeplanner did not take off-street facilities and cut-throughs into account; only streets were considered when calculating distances from home to school. Consequently, actual walking and cycling distances might be shorter than the distances calculated using the online routeplanner.

\section{Conclusions}

In conclusion, the criterion distance for ATS in older Belgian adolescents was set at 8 kilometers in this study. For adolescents living within this distance of their school, gender, smoking status, social modeling and the perception of walkability contributed significantly to the likelihood of ATS. If other studies can confirm these findings, researchers should take these factors into account when developing interventions to enhance ATS and total PA in older adolescents. Of course, in the context of the overall physical activity decline in adolescence, interventions targeting PA behaviors of adolescents living further than eight kilometers from school might also be needed, but these interventions should probably emphasize alternative strategies to increase overall PA.

\section{Acknowledgements \\ The authors want to thank Joris Vandamme, Julie Deman, Tineke Gysel, Dorien Goubert, Nina Van Roosbroek, Laurien Eylenbosch, Jan De Can and Nick Deforce for their assistance in data collection. This research was supported by Research Foundation Flanders (FWO) B/09731/01 and by a post-doctoral fellowship of the Research Foundation Flanders (FWO).}

\section{Author details}

${ }^{1}$ Fund for Scientific Research Flanders (FWO), Brussels, Belgium. ${ }^{2}$ Department of Movement and Sports Sciences, Ghent University, Ghent, Belgium. ${ }^{3}$ Department of Human Biometrics and Biomechanics, Vrije Universiteit Brussels, Brussels, Belgium.

\section{Authors' contributions}

All authors contributed to the design of different parts of the study. DVD coordinated the data collection, conducted the statistical analyses and 
drafted the manuscript. BD developed the data collection protocol and coordinated the data collection. BD, GC and IDB participated in the interpretation of the data, helped to draft the manuscript and revised the manuscript for important intellectual content. All authors read and approved the final manuscript.

\section{Competing interests}

The authors declare that they have no competing interests.

Received: 25 August 2010 Accepted: 8 December 2010 Published: 8 December 2010

\section{References}

1. Pate RR, Freedson PS, Sallis JF, Taylor WC, Sirard J, Trost SG, Dowda M: Compliance with physical activity guidelines: prevalence in a population of children and youth. Ann Epidemiol 2002, 12:303-308.

2. Tudor-Locke C, Ainsworth BE, Adair LS, Popkin BM: Objective physical activity of Filipino youth stratified for commuting to school. Med Sci Sports Exerc 2003, 35:465-471.

3. Alexander LM, Inchley J, Todd J, Curry D, Cooper AR, Currie C: The broader impact of walking to school among adolescents: seven day accelerometry based study. BMJ 2005, 331:1061-1062.

4. Landsberg B, Plachta-Danielzik S, Much D, Johannsen M, Lange D, Müller MJ: Associations between active commuting to school, fat mass and lifestyle factors in adolescents: the Kiel Obesity Prevention Study (KOPS). Eur J Clin Nutr 2008, 62:739-7847.

5. Voss C, Sandercock G: Aerobic fitness and mode of travel to school in English schoolchildren. Med Sci Sports Exerc 2010, 42:281-287.

6. Cooper AR, Wedderkopp N, Wang H, Andersen LB, Froberg K, Page AS: Active travel to school and cardiovascular fitness in Danish children and adolescents. Med Sci Sports Exerc 2006, 38:1724-1731.

7. Sallis JF, Owen N, Fisher EB: Ecological models of health behavior. In Health behavior and health education: theory, research and practice. 4 edition. Edited by: Glanz K, Rimer BK, Viswanath K. San Francisco: JosseyBass; 2008:465-486.

8. Spence JC, Lee RE: Toward a comprehensive model of physical activity. Psychol Sport Exerc 2003, 4:7-24

9. Babey SH, Hastert TA, Huang W, Brown ER: Sociodemographic, family, and environmental factors associated with active commuting to school among US adolescents. J Public Health Policy 2009, 30:S203-S220.

10. Bungum TJ, Lounsbery M, Moonie S, Gast J: Prevalence and correlates of walking and biking to school among adolescents. J Community Health 2009, 34:129-134.

11. Chillon P, Ortega FB, Ruiz JR, Perez IJ, Martin-Matillas M, Valtuena J, et al: Socio-economic factors and active commuting to school in urban Spanish adolescents: the AVENA study. Eur J Publ Health 2009, 19:470-476.

12. Larsen K, Gilliland J, Hess P, Tucker P, Irwin J, He M: The influence of the physical environment and sociodemographic characteristics on children's mode of travel to and from school. Am J Public Health 2009 99:520-526.

13. Mota J, Gomes H, Almeida M, Ribeiro JC, Carvalho J, Santos MP: Active versus passive transportation to school - differences in screen time, socio-economic position and perceived environmental characteristics in adolescent girls. Ann Hum Biol 2007, 34:273-282.

14. Bere E, van der Horst K, Oenema A, Prins R, Brug J: Socio-demographic factors as correlates of active commuting to school in Rotterdam, the Netherlands. Prev Med 2008, 47:412-416.

15. Gorely T, Biddle S, Marshall S, Cameron N, Cassey L: The association between distance to school, physical activity and sedentary behaviors in adolescents: project STIL. Pediatr Exerc Sci 2009, 21:450-461.

16. Nelson NM, Foley E, O'Gorman DJ, Moyna NM, Woods CB: Active commuting to school: how far is too far? Int J Behav Nutr Phys Act 2008, $5: 1$

17. Robertson-Wilson JE, Leatherdale ST, Wong SL: Social-ecological correlates of active commuting to school among high school students. J Adolesc Health 2008, 42:486-495.

18. Telama R: Tracking of physical activity from childhood to adulthood: a review. Obes Facts 2009, 3:187-195.

19. Wengreen $\mathrm{HJ}$, Moncur C: Change in diet, physical activity, and body weight among young-adults during the transition from high school to college. Nutr J 2009, 8:32.
20. Bray SR, Born HA: Transition to university and vigorous physical activity: implications for health and psychological well-being. J Am Coll Health 2004, 52:181-188.

21. Pucher J, Buehler R: Making cycling irresistible: lessons from the Netherlands, Denmark, and Germany. Transport Reviews 2008, 28:495-528.

22. Marfell-Jones M, Olds T, Stewart A, Carter L: International standards for anthropometric assessment ISAK: Potchefstroom, South Africa; 2006.

23. De Bourdeaudhuij I, Lefevre J, Deforche B, Wijndaele K, Matton L, Philippaerts R: Physical activity and psychosocial correlates in normal weight and overweight 11 to 19 year olds. Obes Res 2005, 13:1097-1105.

24. De Bourdeaudhuij I, Sallis JF: Relative contribution of psychological determinants to the prediction of physical activity in three population based samples. Prev Med 2002, 34:279-288.

25. Deforche B, De Bourdeaudhuij I, Tanghe A, Hills AP, Debode P: Changes in physical activity and psychosocial determinants of physical activity in children and adolescents treated for obesity. Patient Educ Couns 2004, 55:407-415.

26. Becker $M H$, Maiman LA: Sociobehavioral determinants of compliance with health care and medical care recommendations. Med Care 1975, 13:10-24.

27. De Bourdeaudhuij I, Sallis JF, Saelens BE: Environmental correlates of physical activity in a sample of Belgian adults. Am J Health Promot 2003, 18:83-92.

28. Trost SG, Owen N, Bauman AE, Sallis JF, Brown W: Correlates of adults' participation in physical activity: review and update. Med Sci Sports Exerc 2002, 34:1996-2001.

29. Frank LD, Sallis JF, Saelens BE, Leary L, Cain K, Conway T, et al: The development of a walkability index: application to the Neighborhood Quality of Life Study. Br J Sports Med 2010.

30. Philippaerts RM, Matton L, Wijndaele K, Balduck AL, De Bourdeaudhuij I, Lefevere J: Validity of a physical activity computer questionnaire in 12to 18-year-old boys and girls. Int J Sports Med 2006, 27:131-136.

31. Santos MP, Oliveira J, Ribeiro JC, Mota J: Active travel to school, BMI and participation in organised and non-organised physical activity among Portuguese adolescents. Prev Med 2009, 49:497-499.

32. Owen N, De Bourdeaudhuij I, Sugiyama T, Leslie E, Cerin E, Van Dyck D, et al: Bicycle use for transport in an Australian and a Belgian city: associations with built-environment attributes. J Urban Health 2010, 87:189-198.

33. Von Rueden U, Gosch A, Rajmil L, Bisegger C, Ravens-Sieberer U, the European KIDSCREEN Group: Socioeconomic determinants of health related quality of life in childhood and adolescence: results from a European study. J Epidemiol Comm Health 2006, 60:130-135.

34. Saelens BE, Sallis JF, Frank LD: Environmental correlates of walking and cycling: Findings from the transportation, urban design, and planning literatures. Ann Behav Med 2003, 25:80-91.

35. Nelson NM, Woods CB: Neighborhood perceptions and active commuting to school among adolescent boys and girls. J Phys Act Health 2010, 7:257-266.

36. Van Dyck D, Cardon G, Deforche B, De Bourdeaudhuij I: Lower neighborhood walkability and longer distance to school are related to physical activity in Belgian adolescents. Prev Med 2009, 48:516-518.

37. Maddison R, Vander Hoorn S, Jian Y, Ni Mhurchu C, Exeter D, Dorey E, et al: The environment and physical activity: the influence of psychosocial, perceived and built environmental factors. Int J Behav Nutr Phys Act 2009, 6:19.

38. Rosenberg D, Ding D, Sallis JF, Kerr J, Norman GJ, Durant N, et al: Neighborhood Environment Walkability Scale for Youth (NEWS-Y): reliability and relationship with physical activity. Prev Med 2009, 49:213-218.

39. Van Sluijs EMF, McMinn AM, Griffin SJ: Effectiveness of interventions to promote physical activity in children and adolescents: systematic review of controlled trials. Br J Sports Med 2008, 42:653-657.

40. Carver A, Timperio A, Hesketh $\mathrm{K}$, Crawford D: Are children and adolescents less active if parents restrict their physical activity and active transport due to perceived risk? Soc Sci Med 2010, 70:1799-1805.

41. Panter JR, Jones AP, Van Sluijs E: Environmental determinants of active travel in youth: a review and framework for future research. Int J Behav Nutr Phys Act 2008, 5:34.

42. Abbott RA, Macdonald D, Nambiar S, Davies PSW: The association between walking to school, daily step counts and meeting step targets in 5- to 17-year-old Australian children. Pediatr Exerc Sci 2009, 21:520-532. 
43. Heelan KA, Donnelly JE, Jacobsen DJ, Mayo MS, Washburn R, Greene L: Active commuting to and from school and BMI in elementary school children - preliminary data. Child Care Health Dev 2005, 31:341-349.

doi:10.1186/1479-5868-7-87

Cite this article as: Van Dyck et al:: Criterion distances and correlates of active transportation to school in Belgian older adolescents. International Journal of Behavioral Nutrition and Physical Activity 2010 7:87.

Submit your next manuscript to BioMed Central and take full advantage of:

- Convenient online submission

- Thorough peer review

- No space constraints or color figure charges

- Immediate publication on acceptance

- Inclusion in PubMed, CAS, Scopus and Google Scholar

- Research which is freely available for redistribution

Submit your manuscript at www.biomedcentral.com/submit
C Biomed Central 